\title{
Review of Contemporary Researches on Physical Education Teachers from a Sociological Perspective
}

\author{
Yanhong Jing \\ School of Physical Education, Jinan University, Guangzhou, China \\ Email: hongyj93@163.com
}

Received 1 June 2016; accepted 8 August 2016; published 11 August 2016

Copyright (C) 2016 by author and Scientific Research Publishing Inc.

This work is licensed under the Creative Commons Attribution International License (CC BY).

http://creativecommons.org/licenses/by/4.0/

c) (i) Open Access

\begin{abstract}
Dramatic changes in education occurred to the western communities during the late $20^{\text {th }}$ century when a considerable number of education reforms were carried out, in which teachers played an essential role. In the issue of education reform, there is significant similarity between contemporary China and western communities. Based on sociological perspective, this article reviews literature of mainstream researches on physical education teachers in the past three decades and summarizes three hot research areas: P.E. teachers' profession development, work environment and their marginalization.
\end{abstract}

\section{Keywords}

Physical Education Teacher, Sociological Perspective, Profession Development, Work Environment, Marginalization

\section{Introduction}

Western communities experienced dramatic changes in education in the $20^{\text {th }}$ century, especially during the period between 1980 and 2000 when a great many education reforms are implemented. This can be illustrated by Education Reform Act passed in July 29, 1988 in Britain, which led to a profound curriculum reform for elementary and middle schools and it has been in effect up until now. In early 80s, a report Core Curriculum for Australian Schools given by Australian Curriculum Development Center (CDC) also marked the beginning of curriculum reform. In America which adopts an education system of decentralization, large-scale education surveys by public service organizations serve as forerunners, followed by the increasing public awareness of the defects in education and therefore the according reforms (Bolton, 2008). These surveys include A Nation at Risk in 1983, A Call for Change in 1985, A Nation Prepared and Tomorrow's Teachers in 1986, Tomorrow's Schools in 1990, Tomorrow's Education College in 1995, No Child Left behind in 2001 and so forth, which have a tre- 
mendously important impact on driving American education reforms. When it comes to athletics, NASPE/ NCATE: Physical Education Guidelines was enacted in 1987 and amended in 1989 and 1992, based on which, Moving into Future: National Standards for Physical Education was put in effect, and it serves as the P.E. standard for American elementary and middle schools. Later, this standard went through its second amendment in 2004 and the third is underway.

Then who plays the key role in this global education reform? A preeminent educationist, Lee S. Shulman points out that although knowledge and teaching are undoubtedly the bedrock of education reform, everything can by no means go anywhere without teachers (Shulman, 1987), which means that education reforms, to a large degree, depend on the teaching quality. Thus, large numbers of researches on teachers were conducted in the late $20^{\text {th }}$ century in western world, whose focuses involved sociology of teachers, professional standards, professional development, evaluation of teaching quality, teachers' reflection practice, collaboration, mobility and so forth. The aim of this research is to improve the quality of teachers and then lay a solid foundation for the implementation of reforms. The same trend was experienced in P.E., which can be illustrated by the articles published in Journal of Teaching in Physical Education (JTPE), the leading journal in P.E. According to Ward, during the period from 1981 to 2005, up to 55\% of JTPE articles were focused on P.E. teachers (Ward \& Ko, 2006). In fact, considering the $8^{\text {th }}$ P.E. basic curriculum reform in 2001 in China as the beginning, Chinese education reform is under the same social circumstance in the past and next 10 years. Thus, there is a need to review the hot researches on P.E. teachers in the end of last century and then to provide implications for Chinese studies in this area.

\section{Research Objects and Methods}

\subsection{Research Objects}

This study focuses on literature on P.E. teachers from a sociological perspective, which are published in major western journals.

\subsection{Research Methods}

\subsubsection{Documentary Analysis}

Selection of database: This study confines the literature source to the following 8 databases: Eric, Academic Search Complete, Education Full text, Medline, Pubmed, PsycINFO, Sportdiscus, Web of Science. b. Selection of literature. This study selects literature by period of publication (from 1970 to 2013), type of journal (peerreviewed academic English journal) and type of literature (on P.E. teachers in western countries) and acquires 1070 articles that meet these requirements. Based on sociological perspective, we first use key words such as "subject”, "socialization”, “marginal” or "induction” to narrow the range. And then two types of result articles will be further excluded: those focusing on administrative employees or other supporting school staff and those focusing on retired teachers instead of in-service teachers. Finally, the result goes down to 54 and these articles serve as the cornerstone of the study. As a result of the selected literature concentrated on 80s and 90s of last century, this study define the period to be late $20^{\text {th }}$ century.

\subsubsection{Logical Analysis}

This article conscientiously examines and analyzes the selected literature by logical analysis and summarizes the main ideas of every article.

\section{Results and Analysis}

After examining literature on P.E. teachers in a sociological fashion, this study identifies 3 hot research areassociological analysis of P.E. teachers’ professional development, sociological analysis of P.E. teachers’ work environment and sociological analysis of teacher marginalization.

\subsection{Sociological Analysis of P.E. Teachers' Professional Development}

\subsubsection{Background of the Sociological Theory}

The sociological analysis of P.E. teachers’ professional development is based on theories of teacher socialization 
which traces as far back as to a book Schoolteacher: A sociological study in 1975 by Lortie. This book is widely considered the most important work that understand how teachers are socialized throughout their entire careers. Lortie's main focus is the various social problems encountered at their work such as the variety of feelings derived from daily work and teachers' particular viewpoints and faiths that can distinguish teaching from other occupations. Most importantly, Lortie proposes a 3-stage theory about teacher socialization: socialization before university, socialization during profession training, socialization at work (Lortie, 1975). socialization before university refers to teaching experience on campus or outside university before the would-be teachers begin to study pedagogy in university. At this stage, there are two main sources of work experience-subjective warrant and apprenticeship observation. Subjective warrant means individuals' subjective perception of teaching tasks and subjective judgments whether they are competent for the teaching tasks. Apprenticeship observation, on the other hand, are related to teachers' viewpoints and faiths toward their jobs through observing their teachers' giving classes during school days. Socialization during profession training is focused on feelings toward teaching work derived from the formal profession training after individuals are accepted to be normal school students, while Socialization at work means their professional development after graduating from normal school and becoming teachers. Overall, Lortie’s research built a solid foundation for researches on teacher socialization.

\subsubsection{Sociological Analysis of P.E. Teachers' Professional Development}

Sociological analysis of P.E. teachers' professional development, simply speaking, is the process of socialization of P.E. teacher. Lawson published 2 articles in 1983 which marked the beginning of study on this area. First, he proposed a model meant to understand socialization of P.E. teacher based on Lorite's work. He argued this process begins at childhood when recreation provides subjective perception of later physical education, and it lasts into P.E. teachers' profession training then into the final stage of when they perform their teaching tasks themselves. Lawson made an assertion that childhood and teenage years, compared to academic years in university, have a even greater impact on P.E. teachers' understanding of physical education and pre-experience of their roles as a teacher (Lawson, 1983a, 1983b). In fact, this standpoint was proven by Feimen and Nemser's general research on teachers which demonstrates that in case of encountering complex teaching situations, newly recruited teachers think first of how they perceived teaching process as a student and then of how they were taught to handle teaching issues by instructors when working as interns in schools (Feimen-Nemser \& Buchmann, 1987). Later, Lawson examined the cumulative effect of P.E. teacher socialization (Lawson, 1983a, 1983b), and he pointed out that after working as teachers for a long time, their manners, performance, beliefs and behaviors will influence their perception of physical education during the socialization process in which most beliefs derive from their own P.E. teachers in school.

In 1988, Lawson further proposed the core framework of P.E. teacher socialization-occupational socialization. He first identified different types of socialization situations that P.E. teachers may come across and provided 11 possible hypotheses which he then categorized and finally came to the conclusion that occupational socialization should be the best way to understand teacher socialization. As he previously defined occupationalization, he believed the concept of occupational socialization is like an umbrella which encompass various socialization. They influences individuals who are entering P.E. and will be responsible for their beliefs and behaviors as teachers or teacher educators. Whether you are a teacher or teacher educator, as long as you are still in this field, occupational socialization will be accompanying you forever (Lawson, 1988). For his point of view, in school, implementation of any P.E. curriculum depends on teachers' proposal and appeal, and simultaneously are subject to a variety of social forces. Occupational socialization can help the following researchers to carry out surveys on the overall social forces that determine P.E. curriculum.

Unlike Lawson's argument, other researchers hold a critical viewpoint on P.E. teacher socialization and they believe P.E. teachers' idea of profession development and values are interactive with the school culture with which they work. Schempp and Graber researched the early stages of socialization and proposed newly recruited teachers' socialization with 4 stages-before university, before occupation, intern experience and entry of occupation (Schempp \& Graber, 1992). From their perspective, at any stage, in order for the environment to meet the perception and expectation of socialization, individuals' beliefs and values will change back and forth repeatedly, which is a dynamic process that form the beliefs and values for later career as P.E. teachers. Further, they believe not only should these philosophies be accepted by normal school students, they are also the outcome of individuals interacting with problems they are faced with. More importantly, university tutors should be 
good at guiding their students in terms of socialization. Schempp, Sparkers and Templin studied their experience and social background as they entered their career. This study is carried out through life history in which three newly employed teachers tell the stories about entry of occupation (Schempp, Sparkers, \& Templin, 1993). They claimed that during the period of adapting to work environment they focus primarily on management skills of their class instead of class content and students' progress. As a result, the subjects they teach and Pedagogical Content Knowledge (PCK) are not fully respected by their colleagues, administrators and parents and thus they fail to receive support and other potential education service. Researchers point out that apparently this dilemma resulted from teachers themselves but in fact reveals Achilles' heel of future training for future P.E. teachers. They urge for effective relationship between universities and schools which can help would-be teachers grapple with a variety of possible challenges during socialization at work.

Wright studied new P.E. teachers' experience involved in socialization. First of all, he argued that these teachers have no idea about their future work - in other words, they show no preference for the role of a teacher or the role of a coach. Moreover, their actions receive insufficient understanding from their colleagues who consider them unable to catch what is called key points. Thus, these teachers express feelings of being isolated, which sharply contrast with the awareness they develop during universities (Wright, 2001). Wright also contended that there should be effective relationship among new teachers, universities and pedagogy during entry of occupation, which is in accord with researches by Schempp.

Naess adopted the educational narrative method to research the everyday life and faith of P.E. teachers during their socialization. This study involved life history of a Norwegian P.E. teachers who all the time love her job and keep passionate for 30 years as if the problems that bother other teachers never exist in her. This is a rare phenomenon and researchers hope to understand the relation between teachers, schools and socialization through observation this particular P.E. teacher. The report shows that she chooses to filter out negative information and build her own positive feelings to keep a good attitude when confronted with various negative information. For instance, when she feels isolated she tends to return to the stadium and stay with students in search of the meaning of heroccupation (Naess, 2001).

This lady, Naess argues, seems to have already overcome obstacles to socialization through ignoring negative information and then build her own positive values. However, this strategy is in fact an escape attitude so he appeals to P.E. teachers that they should challenge this negative force rather than turn a blind eye.

Overall, the researches above reveals the complexity of socialization which involves apprentice's observation, experience of entering career, teachers' faith and values, expectation of teachers, conflicts during socialization and so forth. In the meantime, researchers urge that teachers are supposed to challenge the existing problems and unreasonable factors that limit their socialization and that relation between universities and pedagogy need to be established.

\subsection{Social Analysis of P.E. Teachers' Work Environment}

Work environment and universities structure are important factors that influence P.E. teachers career development. They involve hierarchy between subjects, interaction with other teachers, students, parents and administrators. Related social analysis reached its peak between 80's and late 90's.

Templin pointed out that there are a number of conflicts between P.E. teachers' profession development and school environment. Schools fail to fulfill their duty, which results in P.E. teachers lacking opportunities to reflect on their teaching, receive feedbacks, and examine pedagogy and opportunities to work well with their colleagues, which further affected their satisfaction and efficiency. He believed that compared to the relatively low statue of P.E., these mean more to P.E. teachers. Although they are responsible for job motive and job interest, they receive less support and are more likely to be isolated that their colleagues who teach academic subjects. Under such circumstance, they struggle to tackle problems to increase evaluation from colleagues, which leads to reduction in concern over students. When interaction with other teachers increases, however, the positive effects would bring high-quality teaching and satisfactory atmosphere, which can give a boost to students' performance (Templin, 1988). As a result, he suggests that there needs to be an official organization to promote cooperation between teachers and minimize isolation.

Solmon, worthy and Carter launched research on work environment and role identity of new P.E. teachers. In the first year at work, they turn from a intern teacher to a professional teacher and experience the change in work environment, which enables them to fully understand the role differences. For instance, as an intern teacher, they 
primarily focus on the accumulation of teaching experience, and by the time they enter the career, they would have to invest much of their energy on the "game" with students, colleagues and parents. This is due to the fact that they have to maintain P.E.'s statue as a legitimate subject in school and that they cannot bear to let people consider P.E. inferior. The change in work environment brings shift in role identity. According this study, P.E. teachers express frustration of not being seen as professional because they hope students think of P.E. class as a serious subject rather than a play session. They also share stories about how their colleagues never see them as "real teachers" (Solmon, 1993). Solmon believed that education as a major should help would-be teachers develop ability to shift roles at work.

Stroot, Collier, O’Sullivan and England (1994), however, explored work environment's impact on teachers' perception by examining four factors: purpose of career choices, everyday routine and workload, statue of P.E. in school, interaction with colleagues. (1) The reason for choosing such a career is that they are eager to work with young people in sports and to provide students with chances to be healthy and successful through a variety of activities and experiences. (2) In terms of daily activities, most of work are acceptable to them but non-teaching operational work can be confusing. Also, dual role of a teacher and a coach creates conflicts for them. (3) Because of the low statue of P.E. in school, they believe appropriate recognition can improve teaching quality. (4) They find themselves lacking support from school management, respect from parents and other teachers as well as necessary interaction. Undeniably, participants have different feelings toward interpersonal relationship. Some teachers think their colleagues support them well and are willing to share responsibility with them, whereas others never believe such relationship exist. Considering this, Stroot argued P.E. teachers need to take some strategies for changes and researchers can help them confirm whether or not these strategies really work.

In following studies, Fejgin, Epyraty, Ben-Sira examined the relationship between work environment and occupational burnout. They conducted a questionnaire survey for 150 Israeli P.E. teachers and the result showed that occupational burnout derive from there major factors: unfair financial reward, bureaucracy and psychosocial factor including role conflicts, colleagues' negative opinion of P.E. Like others, this study suggests, pedagogics need to equip would-be teachers with skills to handle role conflicts, and encourage P.E. teachers to take on administrative duty so that they can not only perform better before public in school, but also enter school management and participate in decision making process (Fejgin, Ephraty, \& Ben-Sira, 1994). Revegno and Bandhauerprovided some strategies for P.E. teachers to influence work environment. They studied a P.E. teacher called Dianna who took part in (1) a variety of official committees and projects, (2) voluntary projects with academic teachers, (3) school politics, (4) telling colleagues motivational stories about herself (Rovegno \& Bandhauer, 1997). Revegno and Bandhauer spoke highly of these strategies because they can promote the importance of P.E. and win respect from other teachers. They admitted, however, although these strategies help alter work environment in school to a degree, they do not always work well because of other factors involved.

Overall, these researches indicate that P.E. teachers are likely to be isolated and encounter dilemmas in their work environment. For that there are various reasons such as differences in physical appearance, subject content, subject statues and so forth, to which they also provide some solutions.

\subsection{Social Analysis of P.E. Teachers' Marginalization}

P.E. teachers frequently express discontent about themselves not being seen as legitimate professionals and P.E. being labeled inferior. Their marginalization has always been the focus of research. Hendry was the first to studied the statue of P.E. teachers by providing the concept of marginalization - the role or statue of P.E. is peripheral to academic subjects. The perception that P.E. teachers are inferior professionals is due to the fact P.E. is non-academic. Research showed that P.E. teachers tend to be isolated for three reasons: job responsibility, work place and the way they dress. In terms of job responsibility, other teachers impart academic knowledge in classes while P.E. teachers perform ample seemingly easy physical activities. When it comes to the work place, stadiums normally are far away from school center, which puts P.E. teachers outside public attention and makes them unable to participate in socializing. Finally, unlike academic teachers and principals who usually wear suit and tie, sneakers and T-shirts make P.E. teachers look unprofessional and less educated (Hendry, 1975). Hendry also pointed out that in order to change that situation, some P.E. teachers take pains to fit in with values of academic teachers. This leads them to ignore the fact that what they can do best is to make students take part in physical activities at higher social levels. He believed P.E. teachers should be well aware of their real identity 
and put the focus back on students.

According to a qualitative research by O'Sulivan (1989), two P.E. teachers came across a number of challenges in their first year of career and felt marginalized frequently. They believed their teaching quality was indeed negatively affected by the P.E. subject itself because they had to struggle for legitimate statue "relentlessly" with their colleagues and students. Although these two teachers are recognized as outstanding managers because of their distinguished management of students, they are never considered outstanding teachers. This illustrates that their concern over students receive no understanding and support (O'Sullivan, 1989). Therefore, O’Sullivan came to the conclusion that university teachers in pedagogy department fail to cultivate new teachers because they ignore the importance of understanding new teachers and the challenges they may encounter when they enter their career.

Sparkers and Templin explored P.E. teachers' feelings from perspectives of ego and alter ego. This study examined nine P.E. teachers at all development stages of career from intern teachers to retired teachers to those who switched careers. Results showed that P.E. teachers think of their jobs as professional, subjective, developing, focusing on identity and upholding the worldview of life integrity. Ironically, their colleagues and school management hold the opposite opinion that anything related to P.E. is secondary and fringe. From their perspective, working as P.E. teachers, in essence, is operational, non-intelligent and non-academic. Instead, they are considered practical, normally related to non-academic activities and involving lower social statue (Sparkers, 1990). It leads researchers to believe that this sharp contrast in statues creates frustration and discontent. In the long run, marginalization can have significant negative impact on teachers' satisfaction, job involvement and students' performance. In the following studies, Sparkers, Templin and Schempp found that marginalization involve overlap effects. For example, a female P.E. teacher feels stronger about marginalization than her male counterpart does. However, if this particular female teacher has homosexual tendency, she would experience marginalization in a way that is more obvious and fundamental (Sparkers, Templin, \& Schempp, 1993). By examining factors inductive to marginalization, researchers discovered that combining complexity, dynamicness and interaction involves a number of problems. Based on that, Templin, Grant, and Schempp used case study to illustrate how a P.E. teacher get rid of marginalization by making the best of her role. This teacher with 32 years teaching experience told researchers that he had a deep understanding of discrepancy in statues between a coach and a P.E. teacher. Compared to P.E. teacher who are marginalized and socially inferior, coaches are respected by colleagues and administrators because of distinguished performance of the teams they coach. Hence this teacher shifted the focus to athletic teams and training and he rarely felt marginalized (Templin, Sparkers, Grant, \& Schempp, 1994). On the other hand, Macdonald compare P.E. teachers to proletariats by arguing that the operational and technical work makes P.E. teachers excluded from teacher group just as "proletariats". Evidence about marginalization is everywhere which can influence P.E. teachers' opinion of themselves and their jobs. If their jobs are considered meaningless over a long period of time, they are more likely to leave their current jobs because they can receive more support and more legitimate statues. Due to conflicts between their professional ideals and "proletariats", there is a tension of contradiction among teachers (Macdonald, 1995). However, Macdonald argued this tension of contradiction helps P.E. teachers reflect on the essence of working as a teacher and make themselves more meaningful in school.

Johns and Dimmock focused on the marginalization of P.E. in public schools. They asserted that unlike science, math and other academic subjects that have high self-respect and are commonly seen as effective knowledge, P.E. are labeled non-academic, operational knowledge. This is believed to be a product of deep rooted values influenced by social culture (Johns \& Dimmock, 1999). Johns and Dimmock thus suggested the statue of P.E. should be reconsidered from social and cultural perspectives. (1) They urged to establish a specialized committee to allocate more resource for P.E. and propagate its importance to eliminate negative images. (2) Government decision makers should have a better understanding of the difficulty of challenges facing P.E. teachers at work and create more friendly environment for their career development.

In summary, research in this field demonstrates that as a socially inferior subjects, P.E. teachers who are seen as "proletariats" often experience the feelings of marginalization which usually mingle with gender and sexual orientation. Some strategies should be taken to reduce marginalization to some degree.

\section{Conclusion}

During the late $20^{\text {th }}$ century, researches were carried out mainly from sociological perspective which is deeply 
rooted in western society. Judging from the intrinsic quality, P.E. teachers should be categorized as professionals but they are long considered semi-professional, minor-professional or quasi-professional compared to physicians, engineers and lawyers who are more socially advantaged. During the period of revolution in western education, the urge to promote P.E. teachers' professionalization and improve their statues marks that era. Researchers chose the sociological perspective to research on P.E. teachers, which can be best illustrated by the theory of teacher socialization that is aimed at boosting professionalization for P.E. teachers.

Another characteristic of these researches is qualitative method. Life history, educational narrative, biography and case study play an essential role in studies which highlights the central roles of individuals in research. The best benefit of qualitative method lies in in-depth explanation of existing problems, which is suitable for studies centered on P.E. teachers.

Finally, most of the studies are based on a particular detail from sociological perspective. This can provide a deep understanding of a problem, which reaches to the micro and internal world of individuals and avoids drawbacks brought by black-box methods which only examine two given separate time-points. In fact, this practice can be more enlightening for the following researchers because it turns the camera on micro problems. It can be illustrated by the study on new P.E. teacher's adaptation to work in the first year. Researchers examined a wide range of influencing factors, subjective feelings, others' impression, choices of pedagogy, interaction with others and so forth. By doing this, researchers can reveal the deep covered problems with these new teachers.

\section{References}

Bolton, K. N. (2008). Teacher Education: Assessing the National Standards for Beginning Physical Education Teachers. Urbana-Champaign: University of Illinois.

Feimen-Nemser, S., \& Buchmann, M. (1987). What Is Student Teaching Teacher Education? Teaching and Teacher Education, 3, 255-273. http://dx.doi.org/10.1016/0742-051X(87)90019-9

Fejgin, N., Ephraty, N., \& Ben-Sira, D. (1994). Work Environment and Burnout of Physical Educators. Journal of Teaching in Physical Education, 15, 64-78.

Hendry, L. B. (1975). Survival in a Marginal Role: The Professional Identity of the Physical Education Teacher. The British Journal of Psychology, 26, 465-476. http://dx.doi.org/10.2307/589823

Johns, D. P., \& Dimmock, C. (1999). The Marginalization of Physical Education: Impoverished Curriculum Policy and Practice in Hong Kong. Journal of Educational Policy, 14, 363-384. http://dx.doi.org/10.1080/026809399286242

Lawson, H. (1988). Occupational Socialization, Culture Studies, and the Physical Education Curriculum. Journal of Teaching in Physical Education, 7, 265-288.

Lawson, H. (1983a). Toward a Model of Teacher Socialization in Physical Education: Entry into Schools, Teachers’ Role Orientations, Longevity in Teaching. Journal of Teaching in Physical Education, 3, 3-15.

Lawson, H. (1983b). Toward a Model of Teacher Socialization in Physical Education: The Subjective Warrant, Recruitment, and Teacher Education. Journal of Teaching in Physical Education, 2, 3-16.

Lortie, D. C. (1975). Schoolteacher: A Sociological Study. Chicago, IL: University of Chicago Press.

Macdonald, D. (1995). The Role of Proletarianization in Physical Education Teacher Attrition. Research Quarterly for Exercise and Sport, 66, 129-141. http://dx.doi.org/10.1080/02701367.1995.10762220

Naess, F. (2001). Sharing Stories about the Dialectics of Self and Structure in Teacher Socialization: Revisiting a Norwegian Physical Educator's Life History. European Physical Education Review, 7, 44-61. http://dx.doi.org/10.1177/1356336X010071001

O’Sullivan, M. (1989). Failing Gym Is Like Failing Lunch or Recess: Two Beginning Teachers' Struggle for Legitimacy. Journal of Teaching in Physical Education, 8, 227-242.

Rovegno, I., \& Bandhauer, D. (1997). Norms of School Culture That Facilitated Teacher Adoption and Learning of a Constructivist Approach to Physical Education. Journal of Teaching in Physical Education, 16, 401-425.

Schempp, P., \& Graber, K. (1992). Teacher Socialization from a Dialectical Perspective: Pretraining through Induction. Journal of Teaching in Physical Education, 11, 329-348.

Schempp, P., Sparkers, A., \& Templin, T. (1993). The Micropolitics of Teacher Induction. American Educational Research Journal, 30, 447-472. http://dx.doi.org/10.3102/00028312030003447

Shulman, L. S. (1987). Knowledge and Teaching: Foundations of the New Reform. Harvard Educational Review, 57, 1-23. http://dx.doi.org/10.17763/haer.57.1.j463w79r56455411

Solmon, M., Worthy, T., \& Carter, J. (1993). The Interaction of School Context and Role Identity of First-Year Teachers. 
Journal of Teaching in Physical Education, 12, 313-328.

Sparkers, A. C. (1990). The Problematic Nature of a Career in a Marginal Subject: Some Implications for Teacher Education Programmers. Journal of Education for Teaching, 16, 3-29. http://dx.doi.org/10.1080/0260747900160101

Sparkers, A., Templin, T., \& Schempp, P. (1993). Exploring Dimensions of Marginality: Reflecting on the Life Histories of Physical Education Teachers. Journal of Teaching in Physical Education, 12, 386-398.

Stroot, S., Collier, C., O’Sullivan, M., \& England, C. (1994). Contextual Hoops and Hurdles: Workplace Conditions in Secondary Physical Education. Journal of Teaching in Physical Education, 13, 342-360.

Templin, T. (1988). Teacher Isolation: A Concern for the Collegial Development of Physical Educators. Journal of Teaching in Physical Education, 7, 197-205.

Templin, T., Sparkers, A., Grant, B., \& Schempp, P. (1994). Matching the Self: The Paradoxical Case and Life History of a Late Career Teacher/Coach. Journal of Teaching in Physical Education, 13, 274-294.

Ward, P. C., \& Ko, B. (2006). Publication Trends in the Journal of Teaching in Physical Education from 1981 to 2005. Journal of Teaching in Physical Education, 25, 266-280.

Wright, S. (2001). The Socialization of Singaporean Physical Educators. Journal of Teaching in Physical Education, 20, 207-226.

\section{Submit or recommend next manuscript to SCIRP and we will provide best service for you:}

Accepting pre-submission inquiries through Email, Facebook, LinkedIn, Twitter, etc.

A wide selection of journals (inclusive of 9 subjects, more than 200 journals)

Providing 24-hour high-quality service

User-friendly online submission system

Fair and swift peer-review system

Efficient typesetting and proofreading procedure

Display of the result of downloads and visits, as well as the number of cited articles

Maximum dissemination of your research work

Submit your manuscript at: http://papersubmission.scirp.org/ 